Artigo Original

\title{
Qualidade de vida no trabalho e perfil do estilo de vida individual de professores de Educação Física ao longo da carreira docente
}

\author{
Hudson de Resende Moreira ${ }^{1}$ \\ Juarez Vieira do Nascimento ${ }^{1}$ \\ Christi Noriko Sonoo ${ }^{2}$ \\ Jorge Both ${ }^{1}$ \\ ${ }^{1}$ Programa de Pós-Graduação em Educação Física, Universidade Federal de Santa \\ Catarina, Florianópolis, SC, Brasil \\ 2 Programa de Pós-Graduação em Educação Física, Universidade Estadual de \\ Maringá, PR, Brasil
}

\begin{abstract}
Resumo: O objetivo deste estudo foi analisar a percepção de Qualidade de Vida no Trabalho (QVT), o Estilo de Vida (EV) e suas associações com os Ciclos de Desenvolvimento Profissional (CDP) dos professores de Educação Física da rede estadual do Paraná. A partir do processo de amostragem estratificado e por conglomerados, participaram do estudo 654 professores, sendo 299 do sexo masculino e 355 do sexo feminino. O QVT-PEF (BOTH et al., 2006) e o PEVI (NAHAS et al., 2000) foram empregados na coleta de dados. $\mathrm{Na}$ análise estatística utilizou-se os testes da razão de verossimilhança, regressão logística multinomial, qui-quadrado e qui-quadrado para grupo único. Os resultados revelaram que a maioria dos professores está satisfeita com a QVT e apresenta comportamento positivo quanto ao PEVI. Com o avanço na carreira docente, aumenta a insatisfação da QVT e os comportamentos negativos do PEVI, cuja maior preocupação é o nível de atividade física.
\end{abstract}

Palavras-chave: Qualidade de Vida no Trabalho. Estilo de Vida. Carreira Docente. Educação Física.

\section{Life quality in the work and profile of the teachers' of Physical Education individual lifestyle along the educational career}

\begin{abstract}
The objective of this study was to assess the perception of quality of Working Life (QVT), the Lifestyle $(E V)$ and their associations with the Cycles of Professional Development (CDP) of physical education teachers of the state of Parana. From the process of sampling and stratified by conglomerates, the study involved 654 teachers, of which 299 male and 355 female. The QVT-PEF (BOTH et al., 2006) and PEVI (Nahas et al., 2000) were employed in data collection. Statistical analysis was used to test the likelihood ratio, multinomial logistic regression, chi-square and chi-square for a single group. The results revealed that most teachers are satisfied with the QVT and presented a positive behavior on the PEVI. With the advancement in the teaching profession, increasing the dissatisfaction of the QVT and the negative behaviors of PEVI, whose main concern is the level of physical activity.
\end{abstract}

Key Words: Quality of Working Life. Lifestyle. Teaching Career. Physical Education.

\section{Introdução}

As discussões que norteiam o tema qualidade de vida, na atualidade, dizem respeito à melhoria das condições requeridas para satisfazer as necessidades básicas de determinada sociedade (FERRISS, 2006). Assim, apresentar sugestões que venham ao encontro do processo de equilíbrio entre trabalho e vida saudável tornou-se premissa básica para a melhora da cultura preventiva de males relacionados às atividades laborais, bem como dos aspectos que envolvem tanto a saúde física quanto mental da população.

Nesta perspectiva, o termo qualidade de vida deve estar relacionado ao bem estar e a fatores que não se reportem somente a ausência ou à presença de doenças, mas também à promoção de hábitos que conduzam à boa saúde física e mental, influenciando positivamente a vida do indivíduo (WHO, 1995, PASCOAL et al., 2006).

$$
\text { BOUCHARD e colaboradores }
$$
elaboraram um continuum da saúde, no qual descrevem que a denominada saúde positiva está relacionada à habilidade de 0 indivíduo contemplar, de maneira saudável, o que a vida pode oferecer, superando os desafios do dia a dia. O comportamento de risco está associado a tabagismo; consumo de drogas e de álcool; estresse; falta de atividade física; alimentação inadequada. Uma consequência dos comportamentos de risco é o surgimento de doenças como hipertensão, obesidade, câncer, diabetes, coronariopatias. Os comportamentos de risco provocam a saúde negativa, levando o indivíduo ao outro extremo do continuum, a morte. 
$\mathrm{Na}$ área da Educação Física, uma das definições mais utilizadas é a de NAHAS (2006, p.14), que conceitua qualidade de vida como "a percepção de bem estar resultante de um conjunto de parâmetros individuais e sócioambientais, modificáveis ou não, que caracterizam as condições em que vive o ser humano". Na perspectiva de NAHAS (2006), a qualidade de vida é composta por dois parâmetros. O primeiro é o individual, constituído pela hereditariedade e pelo estilo de vida. Ele tem como componentes: nutrição, atividade física, controle do estresse, comportamentos preventivos e relacionamentos. $O$ segundo parâmetro é vinculado a aspectos socioambientais, expressos pelos indicadores relacionados à educação, segurança, moradia, lazer, trabalho, meio-ambiente.

As condições de vida que o trabalhador docente da Educação Física tem de enfrentar visando desempenhar seu papel de educador, tornam-se cada vez mais desfavoráveis e desmotivantes. Aspectos relacionados aos espaços físicos (MOREIRA et al., 2008, MOREIRA et al., 2004; JAMAL; BABA, 2001; FARIAS et al., 2008), o elevado número de alunos e de aulas ministradas por dia, a baixa e defasada remuneração, a constante cobrança por qualificação profissional, relações interpessoais fragilizadas dentro do ambiente escolar, agressões físicas e morais por parte de pais e alunos (VALLE, 2006; LEMOS, 2007) são possíveis fatores relacionados a transtornos emocionais que interferem na percepção da qualidade de vida no trabalho e no estilo de vida dos docentes (BOTH; NASCIMENTO, 2009).

A carreira docente caracteriza-se por um processo dinâmico que é composto por aspectos relevantes da vida profissional do professor. Estes aspectos interferem diretamente em suas ações, que podem resultar em novas atitudes e condutas. Ela é norteada por conquistas e desafios que podem comprometer o rendimento pedagógico durante a trajetória profissional, provocando mudança de convicções, valores e preparando para os momentos de crise, superação e progresso (CAVACO, 1999; FARIAS et al., 2001; FOLLE et al., 2009, FOLLE; NASCIMENTO, 2008; FARIAS et al., 2008).

Alguns autores (HUBERMAN, 1995; STROOT, 1996; BARONE et al., 1996; NASCIMENTO; GRAÇA, 1998; GONÇALVES, 2000) buscaram delimitar as características apresentadas pelos docentes durante sua carreira profissional. Tais investigações estão baseadas no estudo pioneiro de HUBERMAN (1995), o qual delimitou os ciclos de desenvolvimento profissional dos professores em entrada, estabilização, diversificação ou questionamento, serenidade ou conservantismo e desinvestimento. As etapas acontecem de maneira linear, já que cada professor está inserido em um contexto que possui sua própria característica (HUBERMAN, 1995; NASCIMENTO; GRAÇA, 1998).

Com o objetivo de compreender aspectos positivos e negativos que afetam a trajetória docente, investigações acerca dos ciclos de desenvolvimento profissional evidenciaram que a profissão docente é norteada por avanços, recuos e que o processo de afastamento, em função do término do tempo de serviço profissional, pode ser tranquilo ou traumático, conforme as expectativas pessoais do professor (FOLLE; NASCIMENTO, 2008). Assim, torna-se pontual a averiguação de como o trabalhador docente percebe seu cotidiano no ambiente laboral e como isto tende a afetar sua saúde física e mental (LEMOS, 2007).

Este estudo tem, portanto, como objetivo analisar o nível de percepção de qualidade de vida no trabalho (parâmetro socioambiental), o tipo de comportamento referente ao perfil do estilo de vida individual (parâmetro individual) e suas associações com os ciclos de desenvolvimento profissional dos professores de Educação Física da rede pública estadual de ensino do Paraná.

\section{Métodos}

O estudo caracterizou-se uma pesquisa descritiva de corte transversal. A população foi composta por 4.770 professores efetivos de Educação Física, de ambos os sexos, da rede estadual de ensino do Paraná, oriundos dos 32 Núcleos Regionais de Educação (NREs).

A definição da amostra dos professores ocorreu em dois estágios. O primeiro estágio foi constituído por uma amostragem estratificada, proporcional das regiões geográficas do estado do Paraná. No segundo estágio, utilizou-se o processo de seleção dos NREs por conglomerados.

O cálculo inicial da amostra utilizava um intervalo de confiança de $95 \%$ e um erro amostral de $5 \%$, sendo necessária uma amostra de 356 professores de Educação Física. Foram enviados 2.310 questionários, retornaram respondidos 654 $(28,31 \%)$, estabelecendo um erro amostral de $3,5 \%$.

$\mathrm{Na}$ análise dos ciclos de desenvolvimento profissional utilizou-se o modelo adaptado de NASCIMENTO e Graça (1998), o qual classifica os ciclos em: entrada (0-4 anos de docência), caracterizado pelo período de transição entre a 
saída da formação inicial e a entrada no mercado de trabalho; consolidação (5-9 anos de docência), o docente adquire confiança do conhecimento curricular e pedagógico; diversificação (10-19 anos de docência), o professor considera as atividades que realiza monótonas e repetitivas, momento em que ele busca novas experiências, tanto dentro como fora da escola; estabilização (acima de 20 anos de docência), momento próximo à aposentadoria, caracteriza-se pelo questionamento de sua atuação na escola e na vida pessoal.

O primeiro instrumento aplicado foi a Escala de Avaliação da Qualidade de Vida no Trabalho Percebida por Professores de Educação Física do Ensino Fundamental e Médio (QVT-PEF) (BOTH et al., 2006). Este instrumento é constituído por 34 questões, as quais estão distribuídas em 8 dimensões que foram propostas por Walton (1973): remuneração e compensação: relação entre fatores como salubridade, procura e oferta de serviço, treinamento, capacidade de 0 empregador pagar o empregado, salário médio e o trabalho realizado; condições de trabalho: diz respeito à exposição do professor a locais ou jornadas de trabalho que ponham em risco sua saúde psicológica ou física; oportunidade imediata para uso e desenvolvimento de capacidades humanas: 0 trabalho deve proporcionar ao docente a utilização de suas habilidades e conhecimentos, bem como proporcionar condições para o desenvolvimento de suas capacidades; oportunidade futura de crescimento e segurança: oportuniza ao professor a possibilidade de progressão na carreira; integração social na organização do trabalho: diz respeito aos relacionamentos interpessoais no ambiente escolar; constitucionalismo na organização de trabalho: está relacionado aos direitos e deveres no ambiente escolar; trabalho e espaço total de vida: equilíbrio entre a dedicação profissional e a vida pessoal, tempo dedicado ao lazer; relevância social da vida no trabalho: capacidade que a escola tem de incutir no profissional docente que sua atividade desempenha papel importante na sociedade, bem como à responsabilidade social desempenhada pela própria escola.

O QVT-PEF apresentou elevados índices de concordância entre os especialistas para a validação do conteúdo (acima de $70 \%$ ); valores aceitáveis de reprodutibilidade, uma vez que $94,1 \%$ das questões obtiveram um coeficiente de correlação de Spearman superior a 0,6 e a consistência interna geral do instrumento foi considerada excelente, verificada por meio do Alfa de Cronbach de 0,94 (BOTH et al., 2006).

O segundo instrumento aplicado foi elaborado por Nahas et al. (2000) e denominado Perfil do Estilo de Vida Individual (PEVI). Este questionário é constituído por 15 perguntas, distribuídas em 5 componentes: alimentação, atividade física, comportamento preventivo, relacionamentos e controle do estresse. Os valores de erro padrão, ou seja, da fidedignidade absoluta variam, nos cinco componentes do instrumento, entre 0,29 e 0,44 . Os autores descrevem que, em um instrumento de escala Likert de 0 a 3, estes valores são aceitáveis. No que se refere à fidedignidade relativa, a qual busca verificar a concordância entre duas medidas realizadas, os índices variaram, nos cinco componentes, entre 74\% a 93\% (NAHAS et al., 2000).

$O$ instrumento Perfil do Estilo de Vida Individual possui medidas psicométricas confiáveis. A análise fatorial revelou distribuição similar à proposta original do instrumento, quando considerado o critério de Kaiser. No que diz respeito à sua consistência interna (alfa de Cronbach 0,78$)$, não houve conflito de interesse entre as questões do instrumento $(r s<0,60)$, sendo o questionário considerado apropriado para avaliação do estilo de vida (BOTH et al., 2008c).

A investigação foi realizada após aprovação do projeto pelo Comitê de Ética em Pesquisa com Seres Humanos da Universidade Federal de Santa Catarina (Processo no 036/07). Na coleta de dados foi empregado o malote da Secretaria de Estado da Educação do Paraná para envio dos questionários, acompanhados do termo de consentimento livre e esclarecido, a cada um dos 32 Núcleos Regionais de Ensino (NRE). O retorno dos questionários foi viabilizado por meio do auxílio dos coordenadores de cada NRE.

A tabulação dos dados foi realizada na planilha eletrônica do Microsoft Excel, para a categorização dos dados referentes às dimensões/componentes e dos cômputos gerais da qualidade de vida no trabalho e do estilo de vida, conforme as equações de LEMOS (2007). Foi empregado o teste qui-quadrado para verificar possíveis associações entre os dados sociodemográficos e profissionais e os ciclos de desenvolvimento profissional. Para analisar a distribuição da proporção da amostra de professores, conforme os ciclos de desenvolvimento profissional, utilizou-se o teste qui-quadrado para grupo único, tendo como referência $25,0 \%$.

Para analisar a associação entre os ciclos de desenvolvimento profissional e a qualidade de 
vida no trabalho, bem como do estilo de vida, utilizou-se o teste da razão de verossimilhança. Quando encontrada associação significativa, realizou-se a análise pormenorizada da regressão logística multinomial (odds ratio - OR, com intervalo de 95\% de confiança - IC 95\%). Na análise da regressão logística multinomial foram isolados os professores indecisos e docentes com perfil intermediário, para possibilitar a determinação das razões de chances dos docentes satisfeitos e insatisfeitos e daqueles com perfil positivo e negativo. Todos os testes estatísticos foram realizados no pacote estatístico SPSS, versão 15.0, com um intervalo de confiança de $95 \%$.

\section{Resultados}

Ao analisar as variáveis sociodemográficas e profissionais com os ciclos de desenvolvimento profissional (Tabela 1) constatou-se associação nas variáveis ciclos vitais $(p<0,001)$, estado civil $(p<0,001)$, carga horária $(p<0,001)$, formação $(p<0,001)$ e na distribuição de frequências dos ciclos de desenvolvimento profissional $(p<0,001)$. Observa-se que a maioria dos docentes investigados que possui idade de até 29 anos $(73,7 \%)$ pertence à fase de entrada. Aqueles com idade igual ou superior a 50 anos (85,2\%) encontram-se na fase de estabilização.

Tabela 1. Características Sociodemográficas considerando os Ciclos de Desenvolvimento Profissional.

\begin{tabular}{|c|c|c|c|c|c|}
\hline \multirow{2}{*}{ Variáveis } & \multicolumn{4}{|c|}{ Ciclos de Desenvolvimento Profissional } & \multirow[t]{2}{*}{ p-valor } \\
\hline & Entrada(\%) & Consolidação(\%) & Diversificação(\%) & Estabilização(\%) & \\
\hline Sexo & & & & & $0,391^{*}$ \\
\hline Masculino & 29,1 & 16,2 & 30,1 & 24,7 & \\
\hline Feminino & 26,9 & 13,9 & 36,4 & 22,8 & \\
\hline Ciclo Vital & & & & & $<0,001^{*}$ \\
\hline Até 29 anos & 73,7 & 21,1 & 5,3 & & \\
\hline 30 a 39 anos & 24,3 & 23,0 & 51,5 & 1,3 & \\
\hline 40 a 49 anos & 10,3 & 5,4 & 39,2 & 45,1 & \\
\hline Igual ou superior a 50 anos & 3,1 & 4,6 & 6,2 & 86,2 & \\
\hline Estado Civil & & & & & $<0,001^{*}$ \\
\hline Casado & 20,2 & 15,2 & 37,7 & 27,0 & \\
\hline Outros & 38,8 & 14,6 & 27,3 & 19,2 & \\
\hline Carga Horária & & & & & $<0,001^{*}$ \\
\hline Até 39h & 37,7 & 19,2 & 26,6 & 16,5 & \\
\hline Igual ou superior a 40h & 16,4 & 10,4 & 41,5 & 31,8 & \\
\hline Tempo de Serviço & & & & & $0,140^{*}$ \\
\hline Até 4 anos & 31,3 & 13,5 & 33,7 & 21,5 & \\
\hline 5 a 12 anos & 30,3 & 18,1 & 27,7 & 23,9 & \\
\hline Igual ou superior a de 13 anos & 21,1 & 13,7 & 38,5 & 26,7 & \\
\hline Pluriemprego & & & & & $0,498^{*}$ \\
\hline Não possui & 25,6 & 14,9 & 36,0 & 23,4 & \\
\hline Possui & 30,0 & 15,0 & 30,9 & 24,0 & \\
\hline Regiões do Estado & & & & & $0,107^{*}$ \\
\hline Norte & 20,0 & 13,3 & 37,3 & 29,3 & \\
\hline Noroeste & 26,6 & 11,4 & 39,2 & 22,8 & \\
\hline Oeste & 31,5 & 15,7 & 33,9 & 18,9 & \\
\hline Centro-Sul & 33,7 & 22,1 & 26,0 & 18,3 & \\
\hline Metropolitana litoral & 28,9 & 13,3 & 32,2 & 25,6 & \\
\hline Formação & & & & & $<0,001^{*}$ \\
\hline Graduado & 59,8 & 14,3 & 13,4 & 12,5 & \\
\hline Pós-graduado & 20,2 & 15,4 & 37,9 & 26,5 & \\
\hline Cômputo Geral & 28,0 & 14,5 & 34,2 & 23,3 & $<0,001^{\star *}$ \\
\hline
\end{tabular}

Em relação ao estado civil, a maioria dos professores é casada e a fase de diversificação $(37,7 \%)$ é a que apresenta maior concentração, seguida pela fase de estabilização (27\%). Na fase de entrada $(38,8 \%)$, os docentes apresentam 0 maior percentual de relacionamento diferente do casamento.

A respeito da carga horária semanal de trabalho, o maior contingente de professores que desempenha suas funções laborais em até $39 \mathrm{~h}$ semanais encontra-se na fase de entrada $(37,7 \%)$. Os docentes com carga horária igual ou superior a $40 \mathrm{~h}$ apresentam-se em maior distribuição nas fases de diversificação $(41,5 \%)$ e estabilização (31,8\%).

Quanto à formação acadêmica, a maioria dos docentes da fase de entrada $(59,8 \%)$ possui apenas a graduação. Os docentes pós-graduados concentram-se, em maior número, nas fases de 
diversificação (37,9\%) e de estabilização (26,5\%). A distribuição geral de docentes nos ciclos de desenvolvimento profissional revelou que há maior concentração nos ciclos de diversificação
$(34,2 \%)$ e de entrada (28\%), e menor concentração nas fases de estabilização $(23,3 \%)$ e de consolidação (14,5\%).

Tabela 2. Percepção da Qualidade de Vida no Trabalho considerando os Ciclos de Desenvolvimento Profissional.

\begin{tabular}{|c|c|c|c|c|}
\hline \multirow[t]{2}{*}{ Ciclos de Desenvolvimento Profissional } & \multicolumn{3}{|c|}{ Qualidade de Vida no Trabalho } & \multirow[t]{2}{*}{ p-valor } \\
\hline & Insatisfeito(\%) & Indeciso(\%) & Satisfeito(\%) & \\
\hline \multicolumn{4}{|l|}{ Remuneração e compensação } & \multirow[t]{6}{*}{0,447} \\
\hline Entrada & 43,3 & 36,5 & 20,2 & \\
\hline Consolidação & 35,4 & 43,8 & 20,8 & \\
\hline Diversificação & 48,1 & 32,2 & 19,6 & \\
\hline Estabilização & 47,4 & 2,2 & 20,4 & \\
\hline Total & 44,7 & 35,2 & 20,2 & \\
\hline \multicolumn{4}{|l|}{ Condições de trabalho } & \multirow[t]{6}{*}{0,043} \\
\hline Entrada & 30,2 & 31,8 & 38,0 & \\
\hline Consolidação & 18,6 & 37,1 & 44,3 & \\
\hline Diversificação & 35,5 & 27,1 & 37,4 & \\
\hline Estabilização & 36,8 & 25,0 & 38,2 & \\
\hline Total & 31,8 & 9,4 & 38,8 & \\
\hline \multicolumn{4}{|c|}{ Oportunidade imediata para o uso e desenvolvimento das capacidades humanas } & \multirow[t]{6}{*}{0,001} \\
\hline Entrada & 2,2 & 24,7 & 73,0 & \\
\hline Consolidação & & 13,4 & 86,6 & \\
\hline Diversificação & 5,6 & 19,1 & 75,3 & \\
\hline Estabilização & 7,2 & 25,7 & 67,1 & \\
\hline Total & 4,2 & 21,3 & 74,5 & \\
\hline \multicolumn{4}{|c|}{ Oportunidade futura de crescimento e segurança } & \multirow[t]{6}{*}{0,012} \\
\hline Entrada & 3,9 & 21,9 & 74,2 & \\
\hline Consolidação & 2,1 & 17,5 & 80,4 & \\
\hline Diversificação & 4,2 & 22,3 & 73,5 & \\
\hline Estabilização & 9,2 & 30,7 & 60,1 & \\
\hline Total & 5,0 & 23,5 & 71,5 & \\
\hline \multicolumn{4}{|l|}{ Integração social na organização do trabalho } & \multirow[t]{6}{*}{0,442} \\
\hline Entrada & 10,1 & 36,9 & 53,1 & \\
\hline Consolidação & 7,2 & 34,0 & 58,8 & \\
\hline Diversificação & 10,7 & 39,1 & 50,2 & \\
\hline Estabilização & 14,4 & 39,9 & 45,8 & \\
\hline Total & 10,9 & 37,9 & 51,2 & \\
\hline \multicolumn{4}{|c|}{ Constitucionalismo na organização do trabalho } & \multirow[t]{6}{*}{0,027} \\
\hline Entrada & 4,5 & 15,2 & 80,3 & \\
\hline Consolidação & 1,0 & 15,5 & 83,5 & \\
\hline Diversificação & 6,5 & 19,0 & 74,5 & \\
\hline Estabilização & 10,5 & 19,1 & 70,4 & \\
\hline Total & 6,1 & 17,4 & 76,5 & \\
\hline \multicolumn{4}{|l|}{ Trabalho e espacco total de vida } & \multirow[t]{6}{*}{$<0,001$} \\
\hline Entrada & 14,5 & 27,9 & 57,5 & \\
\hline Consolidação & 15,5 & 23,7 & 60,8 & \\
\hline Diversificação & 24,7 & 35,3 & 40,0 & \\
\hline Estabilização & 28,3 & 32,9 & 38,8 & \\
\hline Total & 21,3 & 30,9 & 47,7 & \\
\hline \multicolumn{4}{|l|}{ Relevância social da vida no trabalho } & \multirow[t]{6}{*}{0,007} \\
\hline Entrada & 3,9 & 14,0 & 82,0 & \\
\hline Consolidação & 2,1 & 13,5 & 84,4 & \\
\hline Diversificação & 4,2 & 17,7 & 78,1 & \\
\hline Estabilização & 11,1 & 21,6 & 67,3 & \\
\hline Total & 5,5 & 17,0 & 77,6 & \\
\hline Avaliação global da qualidade de vida no & abalho & & & 0,001 \\
\hline Entrada & 5,0 & 29,1 & 65,9 & \\
\hline Consolidação & 3,1 & 17,5 & 79,4 & \\
\hline Diversificação & 8,4 & 27,9 & 63,7 & \\
\hline Estabilização & 15,8 & 26,3 & 57,9 & \\
\hline Total & 8,4 & 26,3 & 65,3 & \\
\hline
\end{tabular}

*p-valor estimado pelo Teste de Razão de Verossimilhança.

Os resultados da Tabela 2 indicam que seis em cada dez professores estão satisfeitos com a qualidade de vida no trabalho. Os componentes relevância social da vida no trabalho $(77,6 \%)$ e o constitucionalismo na organização do trabalho $(76,5 \%)$ foram aqueles que os professores investigados apresentaram os níveis de satisfação mais elevados. Por outro lado, os níveis mais baixos de satisfação foram observados nos componentes remuneração e compensação $(20,2 \%)$ e as condições de trabalho $(38,8 \%)$. 
A avaliação global da qualidade de vida no trabalho destacou que os professores da fase de entrada $(5,0 \%)$ apresentaram menor nível de insatisfação que os professores da fase de estabilização (15,8\%, OR=3,56, IC95\%: 1,47$8,60)$. Por outro lado, os professores da fase de consolidação $(79,4 \%)$ relataram estar mais satisfeitos que os demais colegas das fases de entrada (65,9\%, OR=0,51, IC95\%: 0,27-0,94), de diversificação (63,7\%, OR=0,50, IC95\%: 0,27$0,92)$ e de estabilização $(57,9 \%$, OR=0,48, IC $95 \%$ : 0,25-0,91).

Ao analisar a qualidade de vida no trabalho, conforme os ciclos de desenvolvimento profissional (Tabela 2), observou-se a ocorrência de associação significativa nas dimensões condições de trabalho $(p=0,043)$; oportunidade imediata para $o$ uso e desenvolvimento das capacidades humanas $(p=0,001)$; oportunidade futura de crescimento e segurança $(p=0,012)$; constitucionalismo na organização do trabalho $(p=0,027)$; trabalho e espaço total de vida $(p<0,001)$; avaliação global da qualidade de vida no trabalho $(p=0,001)$.

No que diz respeito às condições de trabalho, os professores das fases de diversificação $(35,5 \%, \quad$ OR=2,67, IC95\%: 1,37-5,19) e de estabilização $(36,8 \%, \quad$ OR $=3,02, \quad$ IC95\%: 1,49 $6,11)$ revelaram maior nível de insatisfação do que aqueles que se encontravam na fase de consolidação (18,6\%).

Sobre a oportunidade imediata para o uso e desenvolvimento das capacidades humanas, os docentes da fase de diversificação $(5,6 \%$, OR=3,58, IC95\%: 1,04-12,34) apresentam-se mais insatisfeitos que os professores da entrada da carreira $(2,2 \%)$. Os docentes da fase de consolidação $(86,6 \%)$ demonstraram mais satisfeitos que os professores das fases de entrada $(73,0 \%, O R=0,46, I C 95 \%: 0,23-0,90)$ e de estabilização (67,1\%, OR=0,41, IC95\%: 0,20$0,81)$.

No componente oportunidade futura de crescimento e segurança, evidenciou-se que os professores das fases de entrada (74,2\%, OR=1,73, IC95\%: 1,05-2,86), de consolidação (80,4\%, OR=2,39, IC95\%: 1,27-4,51) e de diversificação (73,4\%, OR=1,70, IC95\%: 1,05$2,74)$ estavam mais satisfeitos que os docentes da fase de estabilização $(60,1 \%)$.

Embora a análise de regressão logística multinomial do componente constitucionalismo na organização do trabalho não tenha detectado a existência de diferença significativa, a análise ampliada do teste da razão de verossimilhança constatou o nível de satisfação entre os docentes das fases de entrada $(80,3 \%)$ e de consolidação $(83,5 \%)$. Nas fases de diversificação $(74,5 \%)$ e de estabilização $(70,4 \%)$ os professores demonstraram estarem menos satisfeitos.

Com relação ao componente trabalho e espaço total de vida, os docentes das fases de diversificação (40,0\%, OR=0,54, IC95\%: 0,34$0,86)$ e de estabilização $(38,8 \%$, OR=0,56, IC $95 \%$ : 0,34-0,94) revelaram menor nível de satisfação que os professores da fase de entrada $(57,5 \%)$. Constatou-se também que os professores das fases de diversificação $(40 \%, O R=0,45, I C 95 \%$ : $0,25-0,80)$ e de estabilização $(38,8 \%$, OR=0,47, IC95\%: 0,25-0,86) demonstraram menor satisfação que os professores da fase de consolidação $(60,8 \%)$.

No componente relevância social da vida no trabalho, os professores da fase de estabilização $(67,3 \%$, OR $=0,54$, IC95\%: 0,30-0,96) relataram estar menos satisfeitos que os professores da fase de entrada (82,0\%).

Em relação ao estilo de vida, constou-se que seis em cada dez professores apresentam perfil positivo quanto ao estilo de vida (Tabela 3 ).

Enquanto que os comportamentos mais positivos foram encontrados nos componentes comportamento preventivo (78,7\%) e relacionamentos $(75,5 \%)$, as condutas mais negativas foram observadas nas dimensões alimentação $(33,6 \%)$ e atividade física $(24,4 \%)$. Destaca-se que somente $51,2 \%$ dos professores relataram a adoção de comportamentos positivos referente ao controle de estresse.

No cômputo geral do estilo de vida, a análise ampliada do teste de razão de verossimilhança detectou fraca associação com os ciclos de desenvolvimento profissional, tendo os professores apresentado menores percentuais de condutas positivas com o decorrer dos anos de docência (entrada $=63,7 \%$; consolidação= $62,9 \%$; diversificação $=59,1 \%$ e estabilização $=59,9 \%$ ). A análise de regressão logística multinomial revelou que os professores da fase de diversificação $(10,2 \%, \quad O R=4,83, \quad$ IC95\%: 1,61-14,53) e de estabilização $(8,6 \%, \quad O R=4,05, \quad$ IC95\%: 1,27 $12,91)$ adotam comportamentos mais negativos que os professores da fase de entrada $(2,2 \%)$ ".

Ao serem avaliadas as dimensões do estilo de vida dos professores de Educação Física, considerando os ciclos de desenvolvimento profissional (Tabela 3), observou-se associação significativa nos componentes atividade física $(p<0,001)$ e fraca associação no componente 
relacionamentos $(p=0,066)$ e na avaliação global

do estilo de vida $(p=0,052)$.

Tabela 3. Comportamento do Perfil do Estilo de Vida Individual considerando os Ciclos de Desenvolvimento Profissional.

\begin{tabular}{|c|c|c|c|c|}
\hline \multirow[t]{2}{*}{ Ciclos de Desenvolvimento Profissional } & \multicolumn{3}{|c|}{ Estilo de Vida } & \multirow[t]{2}{*}{ p-valor } \\
\hline & Negativo(\%) & Intermediário(\%) & Positivo(\%) & \\
\hline Nutrição & & & & 0,433 \\
\hline Entrada & 34,1 & 37,4 & 28,5 & \\
\hline Consolidação & 35,4 & 30,2 & 34,4 & \\
\hline Diversificação & 34,9 & 31,6 & 33,5 & \\
\hline Estabilização & 30,3 & 29,6 & 40,1 & \\
\hline Total & 33,6 & 32,6 & 33,8 & \\
\hline Atividade física & & & & $<0,001$ \\
\hline Entrada & 12,3 & 20,1 & 67,6 & \\
\hline Consolidação & 26,0 & 14,6 & 59,4 & \\
\hline Diversificação & 32,1 & 26,0 & 41,9 & \\
\hline Estabilização & 6,8 & 27,5 & 45,8 & \\
\hline Total & 24,4 & 23,0 & 52,6 & \\
\hline Comportamento preventivo & & & & 0,746 \\
\hline Entrada & 7,3 & 16,8 & 76,0 & \\
\hline Consolidação & 9,3 & 12,4 & 78,4 & \\
\hline Diversificação & 7,4 & 14,4 & 78,1 & \\
\hline Estabilização & 5,9 & 11,2 & 82,9 & \\
\hline Total & 7,3 & 14,0 & 78,7 & \\
\hline Relacionamentos & & & & 0,066 \\
\hline Entrada & 5,1 & 15,2 & 79,8 & \\
\hline Consolidação & 3,1 & 15,6 & 81,3 & \\
\hline Diversificação & 6,5 & 17,7 & 75,8 & \\
\hline Estabilização & 11,1 & 22,2 & 66,7 & \\
\hline Total & 6,7 & 17,8 & 75,5 & \\
\hline Controle do estresse & & & & 0,527 \\
\hline Entrada & 21,8 & 24,6 & 53,6 & \\
\hline Consolidação & 19,6 & 22,7 & 57,7 & \\
\hline Diversificação & 23,7 & 30,7 & 45,6 & \\
\hline Estabilização & 22,4 & 25,7 & 52,0 & \\
\hline Total & 22,2 & 26,6 & 51,2 & \\
\hline Avaliação global do estilo de vida & & & & 0,052 \\
\hline Entrada & 2,2 & 34,1 & 63,7 & \\
\hline Consolidação & 5,2 & 32,0 & 62,9 & \\
\hline Diversificação & 10,2 & 30,7 & 59,1 & \\
\hline Estabilização & 8,6 & 31,6 & 59,9 & \\
\hline Total & 6,8 & 32,0 & 61,1 & \\
\hline
\end{tabular}

* $\mathrm{p}$-valor estimado pelo Teste de Razão de Verossimilhança

Em relação ao componente atividade física, os professores da fase de entrada (12,3\%) relataram comportamentos menos negativos que os demais colegas das fases de consolidação $(26,0 \%$, OR=2,79, IC95\%: 1,21-6,44) e de diversificação (32,1\%, OR=1,96, IC95\%: 1,04-3,70). Por outro lado, os professores das fases de diversificação (41,9\%, OR=0,47, IC95\%: 0,29-0,78; 41,9\%, OR=0,41, IC95\%: 0,21-0,80) e de estabilização $(45,8 \%, \quad$ OR $=0,50, \quad I C=95 \%: 0,29-0,85 ; 45,8 \%$, OR=0,43, IC95\%: 0,21-0,86) apresentaram comportamento menos positivo do que os docentes da fase de entrada $(67,6 \%)$ e de consolidação $(59,4 \%)$, respectivamente.

Sobre o componente relacionamentos, a análise da regressão logística multinomial não identificou associação significativa. A aplicação do teste de razão de verossimilhança revelou fraca associação com os ciclos de desenvolvimento profissional. Nota-se que, com o avançar da carreira docente, os professores parecem adotar comportamentos menos positivos, como foi observado na fase de estabilização $(66,7 \%)$.

\section{Discussão}

Os resultados obtidos revelaram a elevada insatisfação dos professores paranaenses investigados sobre a remuneração e compensação financeira. Apesar de não ter sido observada associação significativa, o nível de insatisfação dos professores parece aumentar com o passar dos anos de docência no magistério público estadual. Apesar dos resultados serem similares aos encontrados em estudos realizados com professores da educação básica (MOLINA NETO, 1998; NILAN, 2003; GOMES et al., 2007; BOTH et al., 2006; KOUSTELIOS, 2005; PAPANASTASIOU; ZEMBYLAS, 2005; JABNOUN; FOOK, 2001; FEJGIN, et al., 1995) e universitária (ROMANZINI, 2005), constata-se que esta situação não se apresenta do mesmo modo em outras unidades federativas, por existirem 
diferentes possibilidades de compensação salarial no magistério público estadual, o que proporciona satisfação com o avanço na carreira docente (LEMOS, 2007; FARIAS et al., 2008).

As evidências encontradas no estudo a respeito das condições de trabalho dos professores são semelhantes aos problemas enfrentados na carreira docente e abordados por diferentes autores, nomeadamente sobre as condições de trabalho, a sobrecarga de atividades oriundas de tarefas administrativas, o número de alunos por turma, a duração da jornada e os turnos de trabalho (KEUNG-FAI, 1996; KOUSTELIOS, 2001; CROSSMAN; HARRIS, 2006). Além disso, percebe-se que o professor tem sido obrigado a uma adaptação cada vez mais emergencial ao mundo globalizado, o que gera a necessidade de ampliar sua jornada de trabalho (CRUZ; LEMOS, 2005).

Apesar de a maioria dos professores paranaenses investigados estarem satisfeitos com suas condições de trabalho, observa-se tendência de equilíbrio entre as percepções de indecisão e insatisfação, semelhante ao verificado nos estudos de LEMOS (2007), Farias et al. (2008) e Both et al. (2006). Algumas investigações têm abordado a desvalorização contínua do professor, que se vê obrigado a trabalhar em condições desfavoráveis à sua prática docente (MOLINA NETO, V., 1998; LAPO; BUENO, 2003; CRUZ; LEMOS, 2005).

A maioria dos professores investigados está satisfeita com os componentes oportunidade imediata para o uso e desenvolvimento das capacidades humanas, oportunidade futura de crescimento e segurança e integração social na organização do trabalho. Apesar de observar um pequeno aumento do nível de satisfação na fase de consolidação, há uma diminuição desta percepção com o avançar da carreira docente. Os resultados encontrados são similares aos estudos de Both et al. (2006) e Gomes et al. (2007) no que se refere a diminuição do nível de satisfação com o passar dos anos de magistério. Os estudos realizados no magistério público do Rio Grande do Sul indicaram uma tendência contrária, ou seja, de aumento do nível de satisfação em tais componentes com o passar dos anos de docência (LEMOS, 2007; FARIAS et al., 2008), que parece ser justificada pelo fato do plano de carreira estadual contemplar, de maneira satisfatória, as expectativas dos professores desta rede de ensino.

O constitucionalismo na organização do trabalho, com foco nos direitos e deveres do professor na escola; o trabalho e espaço total de vida, que retrata o equilíbrio entre o tempo dedicado ao trabalho com o tempo dedicado ao lazer; e a relevância social da vida no trabalho, que aborda como a instituição procura incutir no professor a relevância social de sua atividade são componentes da qualidade de vida no trabalho docente que os professores paranaenses investigados e de outros estudos (BOTH et al., 2006; GOMES et al., 2007) demonstraram estar satisfeitos. Há evidências, no entanto, que o nível de satisfação parece diminuir com o passar dos anos de docência, em oposição ao apresentado por LEMOS (2007) e Farias et al. (2008), que sustentam que a profissão docente, como referido por Nóvoa (1995a), ainda está vinculada à idéia de sacerdócio, dedicação e tentativa de amenizar questões sociais e que as mudanças ocorridas na profissão não têm acompanhado, na mesma proporção, o desenvolvimento de outras áreas do conhecimento e da sociedade (NÓVOA, 1995b). Isto pode ser observado quando a direção escolar solicita ao professor de Educação Física que, além de cumprir sua carga horária na ministração de aulas, organize atividades cívicas, festas de caráter folclórico e artístico, gincanas e atividades esportivas; sem nenhum tipo de compensação (MOLINA NETO, 1998).

De modo geral, a avaliação global da qualidade de vida no trabalho dos professores de Educação Física do Rio Grande do Sul (LEMOS, 2007), Santa Catarina (BOTH et al., 2008a) e Paraná é bastante similar, porque seis de cada dez professores demonstrou estar satisfeito com a qualidade de vida no trabalho.

Ao considerar os ciclos de desenvolvimento profissional, constatou-se que os investigados relataram percepções semelhantes às observadas pelos colegas catarinenses (BOTH et al., 2008a). Enquanto que os professores experientes são os menos satisfeitos, os novatos estão mais satisfeitos com as condições de vida do trabalhador docente. $O$ fato dos docentes gaúchos tornarem-se mais satisfeitos com 0 avançar da carreira docente (FARIAS et al., 2008), novamente parece resultar da aplicação do plano de cargos e salários do magistério estadual, o qual é diferente nos três estados.

Em relação ao estilo de vida dos professores, a preocupação está nos hábitos alimentares relatados pelos investigados, os quais acompanham a tendência de comportamento negativo encontrada com professores de Educação Física do Rio Grande do Sul, de Santa Catarina e da região sudoeste da Bahia (LEMOS et al., 2007; $\underline{B O T H}$ et al., 2007; GOMES et al., 2007). 
Um aspecto a destacar é que, embora não tenha sido encontrada associação significativa, a adoção de comportamentos alimentares positivos parece aumentar com 0 avanço na carreira docente, corroborando os resultados de alguns estudos (BOTH et al., 2007 e GOMES et al., 2007). O aumento de comportamentos alimentares positivos, com o passar dos anos de docência, pode estar vinculado à preocupação com a melhoria ou a manutenção de uma dieta saudável que evite doenças com o avançar dos ciclos vitais (NAHAS, 2006).

A prática de atividades físicas também é um componente preocupante do estilo de vida, apresentando índices elevados de comportamento negativo entre os professores de Educação Física (LEMOS, 2007; LEMOS et al., 2007; BOTH et al., 2007; GOMES et al., 2007, BOTH et al., 2008b). Além disso, os resultados obtidos indicam que, com o avanço da carreira docente, há diminuição dos comportamentos positivos. A queda do vigor físico, o avançar da idade, o pluriemprego, a desmotivação com a profissão e o estresse laboral mostram-se como aspectos determinantes para a ocorrência de comportamento negativo relacionado à prática de atividades físicas (BOTH et al., 2007; BAKKER et al., 2000; GOMES et al., 2006; OZAN, 2009; YUCEL, 2008).

Ao comparar os resultados do componente controle do estresse, constatou-se que os professores paranaenses investigados relataram comportamento mais negativo do que os colegas catarinenses (BOTH et al., 2007) e gaúchos (LEMOS, 2007). Apesar de a maioria dos professores apresentarem comportamento positivo no que se refere à prática de estratégias de enfrentamento de problemas (JESUS, et al.,

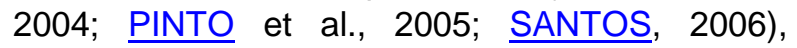
observou-se neste estudo que estes valores diminuem com o avanço na carreira docente.

A prática profissional da docência parece interferir de maneira negativa na vida pessoal dos professores. De modo geral, com o avanço da carreira há tendência em aumentar: a carga horária semanal (NOBLE; MACFARLANE, 2005); a preocupação com salário, segurança e a própria carreira; o nível de desagrado com a quantidade de alunos por turma e o mau comportamento dos discentes(CARLOTTO; PALAZZO, 2006); o nível de insatisfação com uma direção não atuante e com a falta de compromisso da família e do aluno com a escola (MOREIRA et al., 2008; EVERS, et al. 2005); a influência de fatores ambientais como temperatura, umidade, condições do espaço físico laboral e de fatores fisiológicos e biológicos (BOTH; NASCIMENTO, 2009).
A nutrição, a atividade física e o controle do estresse compõem uma tríade e estão diretamente relacionados (NAHAS, 2006). De fato, a prática de atividades físicas que proporcionem satisfação aos praticantes, o uso de técnicas de relaxamento e a adoção de dieta alimentar saudável podem diminuir os efeitos do estresse no organismo (NAHAS, 2006).

No que diz respeito ao comportamento preventivo, os participantes deste estudo relataram a adoção de condutas éticas e sociais aceitáveis e a realização de exames periódicos com o objetivo de monitorar ou identificar possíveis problemas com a saúde. Os comportamentos positivos aumentam com 0 passar dos anos de docência, o que corrobora os resultados encontrados por Both, et al. (2007) e Gomes et al. (2007).

Com o avanço nos anos de docência, constatou-se entre os professores paranaenses investigados que há diminuição dos comportamentos positivos no componente relacionamentos e na avaliação global do estilo de vida. Tais evidências foram encontradas também no estudo com professores do sudoeste da Bahia (GOMES et al., 2007), embora os professores de Santa Catarina tenham apresentado tendência de aumento dos comportamentos positivos (BOTH et al., 2006)

\section{Conclusões}

Considerando as evidências deste estudo e suas limitações metodológicas (emprego de questionários auto-administrados e a participação de professores voluntários), as seguintes conclusões foram elaboradas.

A maioria dos professores investigados de Educação Física do magistério público estadual do Paraná encontra-se satisfeita com a qualidade de vida no trabalho. Entretanto, os professores demonstraram insatisfação com relação à remuneração e compensação (salário médio e o trabalho realizado, salubridade e procura e oferta de serviço), às condições de trabalho (jornadas ou locais de trabalho que afetem seu bem estar físico ou psicológico), à integração social na organização do trabalho (relacionamento com os pares e comunidade) e ao trabalho e espaço total de vida (equilíbrio de tempo dedicado às horas de trabalho com as horas de lazer e convívio familiar).

Ao considerar os ciclos de desenvolvimento profissional, observou-se que aumenta o nível de insatisfação da maioria dos componentes da qualidade de vida no trabalho, excetuando-se os 
componentes remuneração e compensação e integração social na organização do trabalho.

Em relação ao estilo de vida, constatou-se que a maior parte dos professores investigados tem adotado comportamentos positivos. No entanto, comportamentos negativos foram relatados nos componentes nutrição, atividade física e controle do estresse. Destaca-se que os professores mais experientes parecem adotar comportamentos menos positivos no componente atividade física do que os professores novatos.

As futuras investigações, tanto quantitativas quanto qualitativas, necessitam aprofundar esta temática e identificar os fatores que têm provocado insatisfação em determinados componentes da qualidade de vida no trabalho, bem como a adoção de alguns comportamentos negativos do perfil do estilo de vida. Além disso, recomenda-se o desenvolvimento de políticas institucionais de valorização da profissão docente e que proporcionem o aumento do nível de satisfação no ambiente escolar, ao longo da carreira docente no magistério público estadual. Acredita-se que a melhoria da logística laboral e a implementação de planos de carreira, que contemplem tanto a possibilidade de ganho financeiro quanto o investimento pessoal por meio da capacitação periódica dos professores, possam melhorar o nível de satisfação com relação às condições de vida do trabalhador docente.

\section{Referências}

BAKKER, A .B.; SCHAUFELI, E. D.; JANSSEN, P. P. M.; HULST, R. V. D.; BROUWER, J. Using Equity Theory to Examine the Difference between Burnout and Depression. Anxiety, Stress and Coping, Overseas Publishers Association - N.V., v. 13 , p. $247-268,2000$.

BARONE, T., BERLINER, D. C., BLANCHARD, J., CASANOVA, U. ; MCGOWAN, T. A future for education: developing a strong sense of professionalism. In: SIKULA, J.; BUTTERY, T. J.; GUYTON, E. (Org.) Handbook of research on teacher education. New York: Macmillan, 1996, p. 1108-1149.

BOTH, J.; NASCIMENTO, J. V.; LEMOS, C. A. F.; DONEGÁ, A. L.; RAMOS, M. H. K. P.; PETROSKI, E. C.; DUARTE, M. F. S. Qualidade de vida no trabalho percebida por Professores de Educação Física. Revista Brasileira de Cineantropometria e Desempenho Humano, v. 8, n. 2, p. 45-52, 2006. Disponível em: http://www.periodicos.ufsc.br/index.php/rbcdh/artic le/ view/3884/3301. Acesso em: 04 abr. 2008.
BOTH, J.; NASCIMENTO, J. V.; BORGATTO, A. F. Estilo de vida dos professores de Educação Física ao longo da carreira docente no estado de Santa Catarina. Revista Brasileira de Atividade Física e Saúde, v. 12, n. 3 p. 54-64, 2007. Disponível em:

http://www.sbafs.org.br/ artigos/58.pdf . Acesso em: 04 abr. 2008.

BOTH, J.; NASCIMENTO, J. V.; BORGATTO, A. F. Percepção da qualidade de vida no trabalho ao longo da carreira docente em educação física.

Revista Brasileira de Cineantropometria e Desempenho Humano, v. 10, p. 4, p. 372-378, 2008a. Disponível em:

http://www.periodicos.ufsc.br/index.php/rbcdh/artic le/view/372/5866. Acesso em: 20 fev. 2009.

BOTH, J.; NASCIMENTO, J. V.; BORGATTO, A. F. Percepção da qualidade de vida no trabalho e perfil do estilo de vida dos docentes de educação física do estado de Santa Catarina. Revista da Educação Física/UEM, Maringá, v. 19, n. 3, p. 377-389, 3. trim. 2008b. Disponível em: http://www.periodicos.uem.br/ojs/index.php/RevEd ucFis/article/view/5993/3689. Acesso em: 15 dez. 2008.

BOTH, J.; BORGATTO, A. F.; NASCIMENTO, J. V.; SONOO, C. N.; LEMOS, C. A. F.; NAHAS, M.V. Validação da escala "perfil do estilo de vida individual". Revista Brasileira de Atividade

Física e Saúde, v. 13, n. 1, p. 5-14, 2008c. Disponível em:

http://www.sbafs.org.br/ artigos/4.pdf . Acesso em: 20 jan. 2009.

BOTH, J.; NASCIMENTO, J. V. Intervenção Profissional na Educação Física Escolar: considerações sobre o trabalho docente. Movimento, Porto Alegre, v. 15, n. 2, p. 169-186, abr./jun. 2009. Disponível em:

http://www.seer.ufrgs.br/index.php/Movimento/arti cle/viewFile/3046/5140 . Acesso em: 12 ago. 2009.

BOUCHARD, C.; SHEPHARD, R. J.;STEPHANS, T.; SUTTON, R. J.; MCPHERSON, B. D.

Exercise, fitness and health: the consensus statement. In: BOUCHARD, C.; SHEPHARD, R. J.;STEPHANS, T.; SUTTON, R. J.; MCPHERSON, B. D. Exercise, fitness and health. A consensus of current knowledge. Champaign, Illinois, Human Kinetics Publishers, 1990, p. 3-28.

CARLOTTO, M. S.; PALAZZO, L. S. Síndrome de burnout e fatores associados: um estudo epidemiológico com professores. Caderno de Saúde Pública, Rio de Janeiro, v. 22, n. 5, p. 1017-1026, maio, 2006. Disponível em: http://www.scielo.br/pdf/csp/v22n5/14.pdf . Acesso em: 29 abr. 2008. 
CAVACO, M. H. Ofício do professor: o tempo e as mudanças. In: NÓVOA, A. et al. (Org.). Profissão professor. 2. ed. Porto: Porto Editora,1999, p. 57191.

CROSSMAN, A.; HARRIS, P. Job Satisfaction of Secondary School Teachers. Educational Management Administration Leadership, v. 34, n. 1, p. 29-46, 2006. Disponível em; http://ema.sagepub.com/cgi/reprint/34/1/29 . Acesso em: 20 jan. 2009.

CRUZ, R. M.; LEMOS, J. C. Atividade docente, condições de trabalho e processos de saúde. Motrivivência, v. 17, n. 24, p. 59-80, 2005. Disponível em: http://www.periodicos.ufsc.br/index.php/motriviven cia/article/viewFile/742/ 3887. Acesso em: 21 ago 2008.

DELCOR, N. S.; ARAÚJO, T. M.; REIS, E. J. F. B.; PO RTO, L. A.; CARVALHO, F. M.; SI L VA, M. O.; BARBALHO, L.; ANDRADE, J. M. Condições de trabalho e saúde dos professores da rede particular de ensino de Vitória da Conquista, Bahia, Brasil. Caderno de Saúde Pública, Rio de Janeiro, v. 20, n. 1, p. 187-196, jan./fev. 2004. Disponível em: http://www.scielo.br/pdf/csp/v20n1/35.pdf . Acesso em: 21 ago. 2008.

EVERS, W.; TOMIC, W.; BROUWERS, A. Constructive thinking and burnout among secondary school teachers. Social Psychology of Education, v. 8, n. 4, p. 425-439, nov. 2005. Disponível em:

http://www.springerlink.com/content/ f438626221322577/fulltext.pdf. Acesso em: 12 ago. 2008.

FARIAS, G. O.; SHIGUNOV, V.; NASCIMENTO, J. V. Formação e desenvolvimento profissional dos professores de Educação Física. In: SHIGUNOV, V.; SHIGUNOV NETO, A. (Org.). A formação profissional e a prática pedagógica: ênfase nos professores de Educação Física. Londrina: Midiograf, 2001, p. 19-53.

FARIAS, G. O.; LEMOS, C. A. F.; BOTH, J.; NASCIMENTO, J. V.; FOLLE, A. A Carreira docente em educação física: uma abordagem sobre a qualidade de vida no trabalho de professores da rede Estadual de ensino do Rio Grande do Sul. Revista da Educação

Física/UEM, Maringá, v. 19, n. 1, p. 11-22, 1. trim. 2008. Disponível em:

http://periodicos.uem.br/ojs/index.php/RevEducFis larticle/ viewFile/4310/2912. Acesso em: 25 ago. 2008.

FEJGIN, N.; EPHRATY, N.; BEN-SIRA, D. Work Environment and Burnout of Physical Education
Teachers. Journal of Teaching in Physical Education, v. 15, p .64-78, 1995.

FERRISS, A. L. A Theory of Social Structure and the Quality of Life. Applied Research in Quality of Life, Springer Netherlands, v. 1, n. 1, p. 117123, 2006. Disponível em:

http://www.springerlink.com/content/b644142u614 16j6k/ fulltext.pdf . Acesso em: 15 maio 2009.

FOLLE, A.; NASCIMENTO, J. V. Estudos sobre desenvolvimento profissional: da escolha à ruptura da carreira docente. Revista da Educação Física/UEM, Maringá, v. 19, n. 4, p. 605-618, 4. trim. 2008. Disponível em: http://www.periodicos.uem.br/ojs/index.php/RevEd ucFis/article/view/3521/3791. Acesso em: 14 jan. 2009.

FOLLE, A.; FARIAS, G. O.; BOSCATTO, J. D.; NASCIMENTO, J. V. Construção da Carreira Docente em Educação Física: Escolhas, Trajetórias e Perspectivas. Movimento, Porto Alegre, v. 15, n. 1, p. 25-49, jan./mar. 2009. Disponível em: http://www.seer.ufrgs.br/index.php/Movimento/arti cle/view/ 3014/4832. Acesso em: 28 mar. 2009.

GONÇALVES, J. A. M. A carreira das professoras do ensino primário. In: NÓVOA, A. (Org.). Vidas de professores. 2. ed. Porto: Porto Editora, 2000, p. 141-170.

GOMES, A. R.; SILVA, M. J.; MORISCO, S.; SILVA, S.; MOTA, A.; MONTENEGRO, N. Problemas e Desafios no Exercício da Actividade Docente: Um Estudo sobre o Stresse, "Burnout", Saúde Física e Satisfação Profissional em Professores do 3ํㅡㄹ Ciclo e Ensino Secundário. Revista Portuguesa de Educação, Braga Portugal, v. 19, n. 1, p. 67-93, 2006. Disponível em:

https://repositorium.sdum.uminho.pt/bitstream/182 2/5619/1/SO-

Revista\%20Portuguesa\%20de\%20Educa\%c3\%a7 \%c3\%a3o.pdf . Acesso em: 16 set. 2008.

GOMES, M. A.; BORGES, L. J.; NASCIMENTO, J. V. Ciclos de Desenvolvimento Profissional e a Qualidade de Vida de Professores de Educação Física da Região Sudoeste da Bahia. Revista Brasileira de Educação Física, Esporte, Lazer e Dança, v. 2, n. 4, p. 104-114, dez. 2007.

Disponível em:

http://www.refeld.com.br/pdf/21.12.2007/bahia for matado resumo port.pdf. Acesso em: 27 jun. 2008.

HUBERMAN, M. O ciclo de vida profissional dos professores. In: NÓVOA, A. (Org.). Vidas de professores. 2. ed., Porto: Porto Editora, 1995, p. 31-62. 
JABNOUN, N.; FOOK, C. Y. Job satisfaction of secondary school teachers in Selangor, Malaysia. International Journal of Commerce \& Management, v. 11, n. 3/4, p. 72-90, 2001.

JAMAL, M; BABA, V. V. Type-A behavior, job perfomance, and well-being in college teachers. International Journal of Stress Management, Netherlands, v. 8, n. 3, p. 231-240, 2001.

JESUS, S. N.; SANTOS, J. C. V.; STOBÄUS, C. D.; ESTEVE, J. M. Formação em gestão do Stresse. Revista Mal-estar e Subjetividade, v. 4, n. 2, p. 358-371, set. 2004. Disponível em: http://www.unifor.br/notitia/file/186.pdf . Acesso em: 20/07/2007.

KEUNG-FAl, J. W. Job Satisfaction of Hong Kong Secondary School Teachers. Education Journal, v. 24, n. 2, winter, 1996. Disponível em: http://sunzi1.lib.hku.hk/hkjo/view/33/3300613.pdf. Acesso em: 17 mar. 2009.

KOUSTELIOS, A. D. Personal characteristics and job satisfaction of Greek teachers. International Journal of Educational Management, v. 15, n. 7, p. 354-358, 2001. Disponível em: http://www.emeraldinsight.com/Insight/viewPDF.js p?contentType $=$ Article\&Filename $=$ html/Output $/ \mathrm{Pu}$ blished/EmeraldFullTextArticle/Pdf/0600150704.p df. Acesso em: 09 abr. 2009.

KOUSTELIOS, A. D. Physical Education Teachers in Greece: Are they Satisfied? International Journal of Physical Education, v. 42, n. 2, p. 8590, 2005.

LAPO, F. R.; BUENO, B. O. Professores, desencanto com a profissão e abandono do magistério. Cadernos de Pesquisa, n. 118, p. 6588, 2003. Disponível em: http://www.scielo.br/pdf/cp/n118/16830.pdf. Acesso em: 27 ago.2008.

LEMOS, C. A. F. Qualidade de vida na carreira profissional de professores de Educação Física do magistério público estadual/RS. 2007. 144f. Dissertação (Mestrado em Educação Física) - Programa de Pós-Graduação em Educação Física, Centro de Desportos, Universidade Federal de Santa Catarina, Florianópolis, 2007a.

LEMOS, C. A. F.; NASCIMENTO, J. V.; BORGATTO, A. F. Parâmetros individuais e sócio-ambientais da qualidade de vida percebida na carreira docente em educação física. Revista Brasileira de Educação Física e Esporte, São Paulo, v. 21, n. 2, p. 81-93, abr./jun. 2007. Disponível em: http://www.usp.br/eef/rbefe/sumariov21n2/1 v21n 2 p81 93.pdf. Acesso em: 27 maio 2008.
MOLINA NETO, V. A prática dos professores de Educação Física das escolas públicas de Porto Alegre. Movimento, v. 5, n. 9, p. 31-46, 1998.

Disponível em:

http://www.seer.ufrgs.br/index.php/Movimento/arti cle/view/2385/1081. Acesso em: 05 set. 2008.

MOREIRA, H. R; COLLET, C.; FARIAS, G. O.; NASCIMENTO, J. V. Síndrome de burnout em professores de Educação Física: um estudo de casos. Lecturas, Educación Física y

Deportes, Revista Digital. Buenos Aires, ano 13, n. 123, ago. 2008. Disponível em:

http://www.efdeportes.com/efd123/ sindrome-deburnout-em-professores-de-educacao-fisica.htm. Acesso em: set. 2008.

NAHAS, M. V.; BARROS, M. G. V.; FRANCALACCI, V. O pentáculo do bem estar: base conceitual para a avaliação do estilo de vida em indivíduos ou grupos. Revista Brasileira de Atividade Física e Saúde, Londrina, v. 2, n. 5, p. 48-59, 2000.

NAHAS, M. V. Atividade física, saúde e qualidade de vida: conceitos e sugestões para um estilo de vida ativo. 4. ed. Londrina: Midiograf, 2006.

NASCIMENTO, J. V.; GRAÇA, A. A evolução da percepção de competência profissional de professores de Educação Física ao longo da carreira docente. In: Congresso de Educação Física e Ciências do Desporto dos Países de Língua Portuguesa, La Corunha, 1, 1998. Actas do VI Congresso de Educação Física e Ciências do Desporto dos Países de Língua Portuguesa. La Corunha: INEF Galícia, 1998, p. 320-335.

NILAN, P. Teachers' work and schooling in Bali. International Review of Education, v. 49, n. 6, p. 563-584, 2003. Disponível em: http://www.springerlink.com/content/n5437g38492 51112/fulltext.pdf. Acesso em: 19 out. 2008.

NOBLE, K.; MACFARLANE, K. Romance or reality?: Examining burnout in early, childhood teachers. Australin Journal of Early Childhood, v. 30, n. 3, p. 53-58, set. 2005. Disponível em: http://vnweb.hwwilsonweb.com/hww/results/extern al link maincontentframe.jhtml? DARGS $=/ \mathrm{hww} / \mathrm{r}$ esults/results common.jhtml.42 . Acesso em: 20 ago 2009.

NÓVOA, A. Formação de professores e profissão docente. In:_. (Org.). Os professores e a sua formação. Lisboa: Dom Quixote. 1995a.

NÓVOA, A. O passado e o presente dos professores. In: . (Org.). Profissão professor. Porto, Porto Editora. 1995b. 
OZAN, M. B. A study on primary schoolteacher burnout levels:the northern cyprus case.

Education, Chula Vista, California, v. 129, n. 4, p. 629-703, summer 2009. Disponível em:

http://vnweb.hwwilsonweb.com/hww/results/extern al link maincontentframe.jhtml? DARGS=/hww/r esults/results common.jhtml.42. Acesso em: 17 ago. 2009.

PASCOAL, M.; SANTOS, D. S. A.; BROEK, V. V. Qualidade de vida, terceira idade e atividades físicas. Motriz, Rio Claro, v. 12, n. 3, p. 217-228, set./dez. 2006. Disponível em:

http://cecemca.rc.unesp.br/ojs/index.php/motriz/ar ticle/viewFile/413/356. Acesso em: 30 maio 2008.

PAPANASTASIOU, E. C.; ZEMBYLAS, M. Job satisfaction variance among public and private kindergarten school teachers in Cyprus.

International Journal of Educational Research, v. 43, p. 147-167, 2005.

PINTO, A. M.; LIMA, M. L.; SILVA, A. L. Como Lidam os Professores com o Stress Profissional? Coping e Burnout profissional em professores portugueses. Proformar on line, revista bimestral 7. ed., jan. 2005. Disponível em:

http://www.proformar.org/revista/edicao 7/pag 1. htm. Acesso em: 03 ago. 2007.

ROMANZINI, M.; LEGNANI, E.; FONSECA, A. S.; NASCIMENTO, J. V. Quality of life perception at work by physical education university teachers according with the professional development cycle. FIEP Bulletin, v. 75, n. especial, p. 565569, 2005.

SANTOS, G. B. As estratégias de fuga e enfrentamento frente às adversidades do trabalho docente. Estudos e pesquisas em Psicologia, v. 6, n. 1, p. 128-133, jun. 2006. Disponível em: http://pepsic.bvs-psi.org.br/pdf/epp/v6n1/v6n1a 12.pdf . Acesso em: 04/08/2007.

STROOT, S. Organizational socialization: factors impacting beginning teachers. In: SILVERMAN, S.J.; ENNIS, C. (Orgs.). Student Learning in Physical Education. Human kinetics, 1996, p. 339-365.

VALLE, I. R. Carreira do magistério: uma escolha profissional deliberada? Revista Brasileira de Estudos Pedagógicos., Brasília, v. 87, n. 216, p. 178-187, maio/ago. 2006. Disponível em:

http://www.rbep.inep.gov.br/index.php/RBEP/articl e/viewFile/32/34 . Acesso em: 27 nov. 2008.

WALTON, R. E. Quality of working life: what is it? Sloan Management Review. v. 15, n. 1, p. 11-21, 1973.

WHO. (World Health Organization). The World Health Organization Quality of Life Assessement
(WHOQOL): position paper from the World Health Organization. Social Science \& Medicine, v. 41, n. 10, p. 1403-1409, 1995.

YUCEL, C. Teacher burnout and organizational citizenship behavior in turkish elementary school. Educational Planning, v. 17, n. 1, p. 27-43, 2008. Disponível em:

http://vnweb.hwwilsonweb.com/hww/results/extern al link maincontentframe.jhtml? DARGS=/hww/r esults/results common.jhtml.42. Acesso em : 24 maio 2009.

\section{Endereço:}

Hudson de Resende Moreira

Rua Santo Antônio nำ 756, Barreiros

São José SC Brasil

88117-350.

Telefone: (48) 3257.8079 (48) 8406.6667

e-mail: hudsonrm6@yahoo.com.br

Recebido em: 20 de setembro de 2009. Aceito em: 1 de junho de 2010.

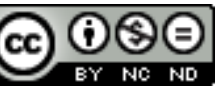

Motriz. Revista de Educação Física. UNESP, Rio Claro, SP, Brasil - elSSN: 1980-6574 - está licenciada sob Licença Creative Commons 